\title{
Irritable Bowel Syndrome among Medical and Non-Medical Northern Border University Students, Kingdom of Saudi Arabia: Across Sectional Study
}

\author{
Nagah Mohamed Abo El-Fetoh1,2, Mohamed Mousa Abd El-Mawgod 3*, \\ Nesreen A. Mohammed ${ }^{4}$, Hanan Saleh A. Alruwaili², Entsar Owaid M. Alanazi² \\ ${ }^{1}$ Public Health and Community Medicine Department, Faculty of Medicine, Sohag University, Sohag, Egypt \\ ${ }^{2}$ Northern border University, Arar, KSA \\ ${ }^{3}$ Public Health and Community Medicine Department, Faculty of Medicine, Al-Azhar University, Assiut, Egypt \\ ${ }^{4}$ Public Health, Faculty of Medicine, Sohag University, Sohag, Egypt \\ Email: elshmaa3332004@yahoo.com, ”mossa20072006@yahoo.com, nesreenhammad180@yahoo.com, \\ Hsa-e@hotmail.com, al-maaas.2010@hotmail.comr
}

Received 4 May 2016; accepted 20 June 2016; published 23 June 2016

Copyright (C) 2016 by authors and Scientific Research Publishing Inc. This work is licensed under the Creative Commons Attribution International License (CC BY). http://creativecommons.org/licenses/by/4.0/

\section{(c) (i) Open Access}

\section{Abstract}

Background: Irritable Bowel Syndrome (IBS) is a common functional gastrointestinal disorder (FGID), characterized by abdominal pain or discomfort and alteration in bowel habits. Aim of the study: To determine the overall prevalence, prevalence of each type and risk factors of IBS among Northern Border University ( $\underline{\mathrm{NBU}}$ ) students, Arar, Kingdom of Saudi Arabia. Material and methods: We use cross sectional, descriptive study with multistage cluster probability sample. Using Rome III criteria questionnaire of IBS; which is a self-administrated consists of ten questions assessing the current status of an apparently normal person. The questionnaire is administrated to Northern Border University students. Results: A total of 228 University students of them, 94 (41.2\%) males and $134(58.8 \%)$ females were included in the study. The overall prevalence of IBS according to Rome III criteria in northern border University was $(32.5 \%)$. The disease prevalence was $33.6 \%$ in females and $30.9 \%$ in males. Among the study participants, the most common type of IBS was the mixed one $12.7 \%$, followed by the constipation predominant type $10.5 \%$, then the diarrhea predominant type $5.7 \%$ while the least common was un-subtyped cases $(3.5 \%)$. Statistically significant increase in prevalence of this disease was found among female students $(60.8 \% \mathrm{vs}$. $39.2 \%$ in males) (p-value < 0.05), the students who experienced psychic stress and irritability $(79.7 \%)$ (p-value $<0.05$ ) and students who were obese (p-value $<0.001)$. Conclusion: The results

\footnotetext{
${ }^{*}$ Corresponding author.

How to cite this paper: El-Fetoh, N.M.A., et al. (2016) Irritable Bowel Syndrome among Medical and Non-Medical Northern Border University Students, Kingdom of Saudi Arabia: Across Sectional Study. Open Journal of Gastroenterology, 6, $188-195$. http://dx.doi.org/10.4236/ojgas.2016.66024
} 
of this study concluded the prevalence rate of $32.5 \%$ for IBS among the students studying in Northern Border University. Stress and high body mass index were significantly associated with IBS. In addition, this study concluded that IBS was not significantly associated with socio-demographic characteristics and smoking.

\title{
Keywords
}

\author{
Prevalence, Irritable Bowel Syndrome, IBS, Rome III Criteria
}

\section{Introduction}

Irritable Bowel Syndrome (IBS) is a common functional gastrointestinal disorder (FGID), characterized by abdominal pain or discomfort and alteration in bowel habits [1].

Altered gastrointestinal motility, visceral hypersensitivity, post-infectious reactivity, brain-gut interactions, alteration in gut microbiota, food sensitivity, dietary intakes, and intestinal inflammation have been linked to the pathogenesis of IBS [2].

IBS affects as many as $5 \%-20 \%$ of individuals worldwide. It is more prevalent in women than men, and is more commonly diagnosed in patients younger than 50 years of age [3].

IBS imposes a significant burden on patients and healthcare systems due to its prevalence and lack of successful treatments [4]. It is one of the most common outpatient diagnoses in primary care and gastroenterology [5].

Most people with IBS have mild symptoms. Many people don't recognize IBS symptoms. Yet, IBS is one of the most common disorders seen by physicians. Not all individuals with IBS symptoms seek medical care for their symptoms. Nevertheless, there are between 2.4 and 3.5 million annual physician visits for IBS in the United States alone. IBS is the most common disorder diagnosed by gastroenterologists and accounts for up to $12 \%$ of total visits to primary care providers [6].

A significant proportion-35\% to $40 \%$ - of individuals who report IBS in the community are male. Approximately $60 \%$ to $65 \%$ of individuals who report IBS in the community are female [6].

There are not many studies that include both medical and non-medical students together. Similar studies about the prevalence of IBS among medical students from South America [7], Pakistan [8], Saudi Arabia [9] reveal prevalence rates of $21 \%, 28.3 \%, 31.8 \%$ consequently.

A study was conducted in Egypt by Ahamed et al. in an urban area in Suez governorate from January 2008 to August 2009. 117 individuals were included in this study. Rome II criteria were used for the diagnosis of IBS. The prevalence of IBS among the study sample was 34.2\% [10].

Another study was conducted in Sues, Egypt, aimed to explore the prevalence of irritable bowel syndrome (IBS) among Suez Canal university students. Using Rome criteria III IBS module, total (170) students (whose mean age is $20 \pm 0.82$ ), the prevalence of IBS according to Rome III criteria in Suez Canal University is $22.9 \%$. $23.8 \%$ are diseased in the faculty of commerce while $22.1 \%$ in faculty of medicine. Females in this study represent $64.1 \%$ of the sample, $30.3 \%$ of them are diseased, while males represent $35.9 \%$ about $9.8 \%$ of them are diseased. IBS constipation predominant type is $28.2 \%$, diarrhea predominant type is $15.4 \%$, mixed type is $46.2 \%$, and the un-subtyped cases represent $10.3 \%$ [11].

Findings from a cross-sectional study to assess the prevalence and factors associated with irritable bowel syndrome among university students in Lebanon reported that an overall prevalence of IBS of $20 \%$ was recorded among university students, females were significantly more likely to report having IBS than males (29.1\% vs $18.2 \%, P<0.01)$. Those living at the school dormitory or in a private residence (39.5\%) were more likely to have IBS than those living with their families $(16.3 \%)(P<0.01)$. The multivariate analysis showed that those who had a relatively high family income level (US\$ > 2000) were almost 6 times more likely to report having IBS than their counterparts [12]. [13]:

IBS sub classification According to the Rome III criteria, and on the basis of the patient's stool characteristics

- IBS with diarrhea (IBS-D):

- Loose stools $>25 \%$ of the time and hard stools $<25 \%$ of the time.

- Up to one-third of cases. 
- More common in men.

- IBS with constipation (IBS-C):

- Hard stools $>25 \%$ of the time and loose stools $<25 \%$ of the time.

- Up to one-third of cases.

- More common in women.

- IBS with mixed bowel habits or cyclic pattern (IBS-M):

- Both hard and soft stools $>25 \%$ of the time.

\section{Aim of the Study}

To determine the overall prevalence, prevalence of each type and risk factors of IBS among Northern Border University students, Arar, Kingdom of Saudi Arabia.

\section{Material and Methods}

Type of the study: Cross sectional, descriptive study.

Sampling: Multistage cluster probability sample.

Using Rome III criteria questionnaire of IBS; which is a self-administrated consists of ten questions assessing the current status of an apparently normal person. Each question can be answered according to a scale describing the frequency of experiencing each symptom.

According to Rome III criteria, IBS is defined as recurrent abdominal pain or discomfort at least 3 days per month in the last 3 months associated with two or more of the following:

1) Improvement with defecation;

2) Onset associated with a change in frequency of stools;

3) Onset associated with a change in form (appearance of stool).

Also, these criteria should be fulfilled for the last 3 months with symptom onset at least 6 months before diagnosis [14] [15].

The questionnaire was distributed to Northern Border University students; 250 questionnaires were distributed but only 228 completely filled and returned to us with a response (91.2\%), a population consisting of (125) students of the faculty of medicine \& non-medical (103) students of the faculty of Education with total (228), during the period from November 2015 to April 2016.

The questionnaire included question about socio-demographic characteristics of the participants, including age, sex, marital status and average family income per month. Data of Rome III criteria questionnaire of IBS were included in addition to history of repeated exposure to stress and sense of irritability, history of smoking, height and weight for body mass index (BMI).

Participants were provided with the questionnaire and they gave it back at the same day. Well trained data collecting team were responsible for distributing the questionnaire and providing help while participants filling it.

\section{Ethical Considerations}

This study was reviewed and approved by the Research Ethics Committee of Faculty of Medicine, Northern Border University. Participants were informed that participation is completely voluntary, and written consent was obtained from each participant before being subjected to the questionnaire and after discussing the objective with the participants. No names were recorded on the questionnaires. All questionnaires were kept safe.

\section{Statistical Analysis}

Data were analyzed using statistical package for social science (SPSS) version 16.comparison between groups was assessed using the chi-squared test, with a 95\% confidence interval (CI), p-value less than 0.05 was considered statistical significant.

\section{Results}

In Table 1, this study included 228University students of them, 92 (41.2\%) males and 134 (58.8\%) females. The overwhelming majority (98.2\%) of participants were equal or less than 25 years old, single students were $92.1 \%$ compared to married $7.9 \%$. 
Table 1. Socio-demographic characters, BMI, stress and smoking history of medical and non medical students of NBU, Arar, KSA, 2016.

\begin{tabular}{|c|c|c|}
\hline Parameter & No. & $\%$ \\
\hline \multicolumn{3}{|l|}{ Age } \\
\hline$\leq 25$ & 224 & 98.2 \\
\hline$>25$ & 4 & 1.7 \\
\hline \multicolumn{3}{|l|}{ Sex } \\
\hline Male & 92 & 41.2 \\
\hline Female & 134 & 58.8 \\
\hline \multicolumn{3}{|l|}{ Marital status } \\
\hline Single & 210 & 92.1 \\
\hline Married & 18 & 7.9 \\
\hline \multicolumn{3}{|l|}{ Family income } \\
\hline $2000 \mathrm{SR}^{*}$ & 20 & 8.8 \\
\hline 8000 SR or more & 208 & 91.3 \\
\hline \multicolumn{3}{|c|}{ Body mass index (BMI) } \\
\hline$<18.5$ & 12 & 5.2 \\
\hline $18.5-24.9$ & 79 & 34.6 \\
\hline $25-29.9$ & 63 & 27.6 \\
\hline $30-34.9$ & 44 & 19.3 \\
\hline$>35$ & 30 & 13.2 \\
\hline \multicolumn{3}{|c|}{ Psychic stress and irritability } \\
\hline Yes & 136 & 59.6 \\
\hline No & 92 & 40.4 \\
\hline \multicolumn{3}{|l|}{ Smoking } \\
\hline Yes & 3 & 1.3 \\
\hline No & 225 & 98.7 \\
\hline
\end{tabular}

$\mathrm{SR}^{*}$ Saudi Ryal.

With regard to BMI, nearly one third (34.6\%) of the students were normal compared to more or less similar percentage obese (32.5\%) and small percentage (5.2\%) underweight.

The majority of respondents (59.6\%) reported having psychic stress and irritability, while smoking reported only in small percentage of them $(1.3 \%)$.

Table 2 illustrates the prevalence of IBS between medical and non medical students of NBU. Regarding the prevalence of irritable bowel syndrome, the students who are not diseased were more than those who were diseased as the not diseased students were $67.5 \%$ while the diseased were $32.5 \%$. Disease prevalence was $33.6 \%$ in females and $30.9 \%$ in males. Among the study participants, the most common type of IBS was the mixed one $12.7 \%$, followed by the constipation predominant type $10.5 \%$, then the diarrhea predominant type $5.7 \%$ while the least common is un-subtyped cases (3.5\%).

Table 3 illustrates the prevalence of types of Irritable Bowel Syndrome (IBS) and distribution of found cases regarding colleges of NBU. Of the found cases among students, it is obvious from the table and (Figure 1) that, more than one third (39.2\%) had a mixed IBS type followed by constipation predominant IBS in nearly one third $32.4 \%$, diarrhea predominant in nearly one fifth and lastly small percentage (10.8\%) un-subtyped. Regarding distribution of IBS found cases according to colleges, it is clear from the table and (Figure 2) that, from 74 cases there was 23 (31\%) of cases medical and 41 (69\%) non medical students.

Table 4 shows the relation between the IBS and socio-demographic characters, smoking, psychic stress and BMI among the studied students. IBS was not significantly associated with age, marital status, smoking and income of the participant. However, statistically significant increased prevalence of this disease was found among 
Table 2. The prevalence of Irritable Bowel Syndrome (IBS) and its types between medical and non medical students of NBU, Arar, KSA, $2016(n=228)$.

\begin{tabular}{lll}
\hline Parameter & No. & $\%$ \\
\hline IBS among the total number of participants & 154 & 67.5 \\
Not diseased & 74 & 32.5 \\
Diseased & & \\
Types of IBS among the total number of participants & 154 & 67.5 \\
Not diseased & 29 & 12.7 \\
Mixed & 24 & 10.5 \\
Constipation predominant & 13 & 5.7 \\
Diarrhea predominant & 8 & 3.5 \\
Un-subtyped & & 33.6 \\
Distribution of IBS found cases regarding sex & 29 & \\
In males (n = 94) & 45 & 30.9 \\
In females (n = 134) & & 33 \\
\hline
\end{tabular}

Table 3. The prevalence of types of Irritable Bowel Syndrome (IBS) and distribution of found cases regarding colleges of NBU, Arar, KSA, $2016(n=74)$.

\begin{tabular}{lll}
\hline Parameter & No. & $\%$ \\
\hline Types of IBS among the found cases $(\mathbf{n}=\mathbf{7 4})$ & & 39.2 \\
Mixed & 29 & 32.4 \\
Constipation predominant & 24 & 17.6 \\
Diarrhea predominant & 13 & 10.8 \\
Un-subtyped & 8 & \\
Distribution of IBS found cases regarding colleges $(\mathbf{n}=\mathbf{7 4})$ & & 31 \\
Medical & 23 & 69 \\
Non-medical & 41 & \\
\hline
\end{tabular}

female students (60.8\%) (p-value $<0.05)$, the students who experienced Psychic stress and irritability (79.7\%) (p-value $<0.05$ ) and student who are obese (p-value $<0.001$ ).

\section{Discussion}

This study was conducted to determine the prevalence of IBS among Northern Border University students through the Rome III criteria IBS module. The prevalence of IBS according to the present study was 32.5\% which is in line with the finding of a cross-sectional study conducted among medical students and interns at King Abdulaziz University, Jeddah by Ibrahim et al. [9] where the prevalence of IBS was $31.8 \%$. In addition, the finding of the current study is consistent with the findings of Ahmed et al. [10] who conducted a study in an urban area in Suez governorate and found that the prevalence of IBS among the studied population was 34.2\%.

On the other hand, the prevalence of IBS in the current study is higher than the findings of Darweesh et al. [11] who conducted a study among students in Suez Canal University, Egypt and revealed that only 22.9\% of the studied students were diseased and the findings of a study conducted in Karachi, Pakistan by Naeem et al. [16] where the prevalence of IBS was found to be $28.3 \%$. 


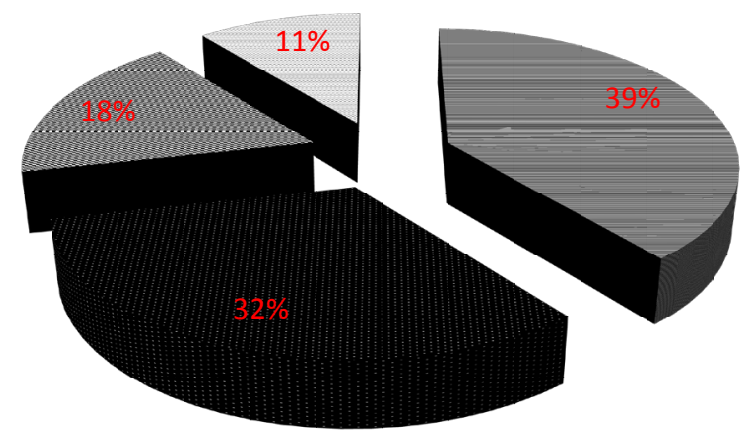

\section{EMixed E Constipation predominant $\quad \square$ Diarrhea predominant $\quad$. Un-subtyped}

Figure 1. Types of IBS among the diseased students $n=74$.

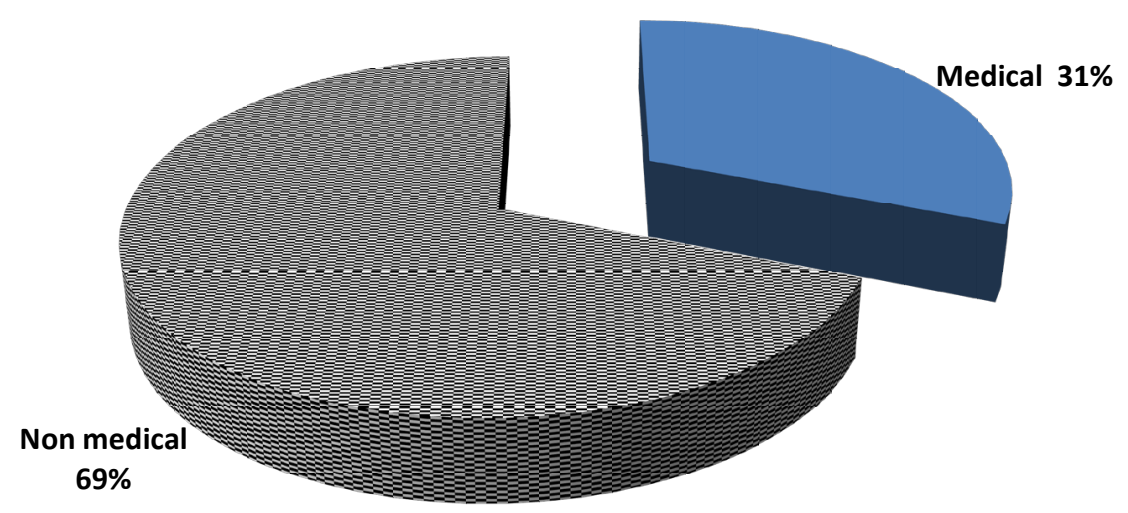

Figure 2. Prevalence of IBS among medical and none medical students $n=74$.

Results revealed that $39.2 \%$ of the diseased students had a mixed IBS type and 32.4\% had constipation predominant IBS which is inconsistent with the findings of a study conducted among Japanese university students by Shiotani A et al. [17] who revealed that the constipation predominant type was more prevalent (47.8\%). However, findings of the present study is in agreement with the results revealed by Naeem et al. [16] where the most common type was the mixed IBS type followed by constipation predominant IBS.

As regards the relationship between socio-demographic characteristics and irritable bowel syndrome among the studied students, our study revealed that no significant relation between them, this is in agreement with Al-Ghamdi, et al. [18] who revealed that age, marital status and smoking had no significant effect on the presence of IBS in a cross sectional study conducted on medical student studying in Prince Sattam bin Abdulaziz University, Al-Kharj, Saudi Arabia. On the other hand, Naeem et al. [16] found that age was significantly associated with the prevalence of IBS where $60.7 \%$ of the individuals associated with IBS belonged to age-group 21 - 23 years followed by age-group 18 - 20 years (33.3\%). In another study conducted by Liu et al. [19], age had a significant effect on IBS.

In the current study, stress among the students, regardless of its source was proved to be a major risk factor associated with the development of irritable bowel syndrome, interestingly this consistent with Al-Ghamdi, et al. [18].

The present study revealed a significant effect of body mass index $(P=0.031)$ on the prevalence of the disease between the respondents. This finding is consistent with Ibrahim et al. [9] where BMI of respondents significantly affected the prevalence of IBS. On the other hand, Liu et al. [19] revealed that BMI had no significant effect on IBS prevalence.

\section{Conclusion}

The results of this study concluded the prevalence rate of $32.5 \%$ for IBS among the students studying in Northern 
Table 4. The relationship between socio-demographic characteristics and irritable bowel syndrome among the studied females, Arar, KSA, 2016.

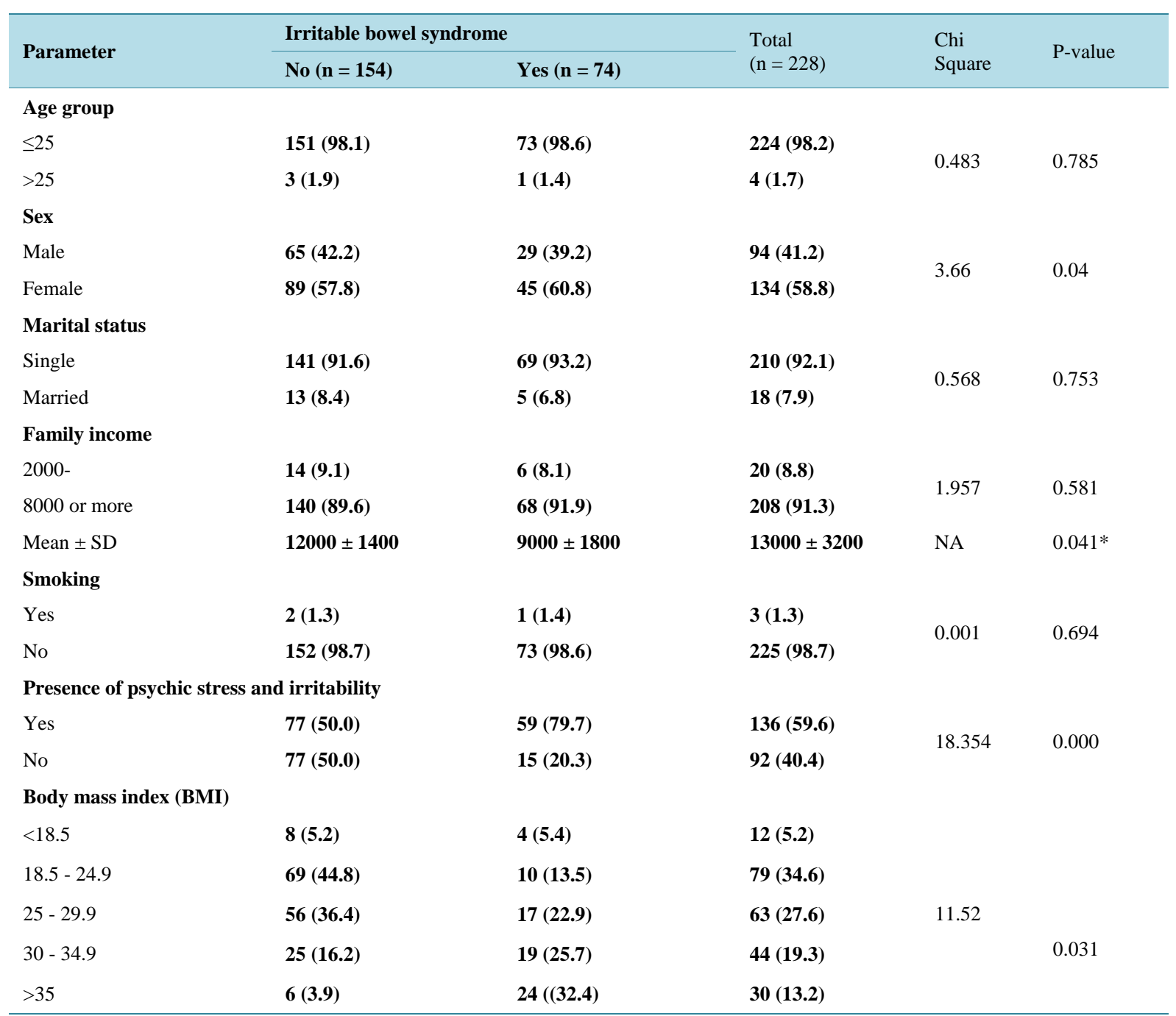

*Independent sample t test was used.

Border University. Stress and high body mass index were significantly associated with IBS. In addition, this study concluded that IBS was not significantly associated with socio-demographic characteristics and smoking.

\section{Recommendations}

1) It is recommended to use screening approach for IBS and related psychological symptoms and problems.

2) In order to make the students capable to cope up and overcome the stressors during their studies or assignment or work, there is a primary requirement of stress management courses.

\section{Conflict of Interests}

The authors have not declared any conflict of interests.

\section{References}

[1] Spiller, R.C. (2011) Irritable Bowel Syndrome: Gender, Infection, Lifestyle or What Else? Digestive Diseases, 29, 215221. http://dx.doi.org/10.1159/000323924 
[2] Occhipinti, K. and Smith, J.W. (2012) Irritable Bowel Syndrome: A Review and Update. Clinics in Colon and Rectal Surgery, 25, 46-52. http://dx.doi.org/10.1055/s-0032-1301759

[3] El-Salhy, M. (2012) Irritable Bowel Syndrome: Diagnosis and Pathogenesis. World Journal of Gastroenterology, 18, 5151-5163.

[4] Jung, H.K., Kim, Y.H., Park, J.Y., et al. (2014) Estimating the Burden of Irritable Bowel Syndrome: Analysis of a Nationwide Korean Database. Journal of Neurogastroenterology and Motility, 20, 242-252. http://dx.doi.org/10.5056/jnm.2014.20.2.242

[5] Nellesen, D., Yee, K., Chawla, A., et al. (2013) A Systematic Review of the Economic and Humanistic Burden of Illness in Irritable Bowel Syndrome and Chronic Constipation. Journal of Managed Care Pharmacy, 19, 755-764. http://dx.doi.org/10.18553/jmcp.2013.19.9.755

[6] About, I.B.S. (2013) What’s IBS, Statistics. http://www.aboutibs.org/site/what-is-ibs/facts/statistics

[7] Machicado, J.D., Galvez, J.V., Marcos, L.A., et al. (2013) Prevalence of Irritable Bowel Syndrome in South America. Clinical Gastroenterology \& Hepatology, 11, 102. http://dx.doi.org/10.1016/j.cgh.2012.08.016

[8] Saito, Y.A., Petersen, G.M., Larson, J.J., Atkinson, E.J., Fridley, B.L., de Andrade, M., et al. (2010) Familial Aggregation of Irritable Bowel Syndrome: A Family Case-Control Study. American Journal of Gastroenterology, 105, 833841. http://dx.doi.org/10.1038/ajg.2010.116

[9] Ibrahim, N.K.R., Battarjee, W.F., Almahdi, S.A., et al. (2013) Prevalence and Predictors of Irritable Bowel Syndrome among Medical Students and Interns in King Abdul-Aziz University, Jeddah, Saudi Arabia. Libyan Journal of Medicine, 8, Article ID: 21287.

[10] Ahmed, A., Mohamed, R.A., Sliem, H.A. and Nour Eldein, N.E. (2011) Pattern of Irritable Bowel Syndrome and Its Impact on Quality of Life in Primary Health Care Center Attendees, Suez Governorate, Egypt. The Pan African Medical Journal, 9, 5. http://dx.doi.org/10.4314/pamj.v9i1.71177

[11] Darweesh, M.M., Abd El Hameed, M.M., Hassan, Y.M., Abd El Rheem, K.A., Mohamed, S.A., Mahdy, M.A., Slwawy, A.A. and Abo El Ftooh, M.M. (2015) The Prevalence of Irritable Bowel Syndrome among Medical and NonMedical Suez Canal University Students. Open Journal of Gastroenterology, 5, 42-48. http://dx.doi.org/10.4236/ojgas.2015.55009

[12] Costanian, C., Tamim, H. and Assaad, S. (2015) Prevalence and Factors Associated with Irritable Bowel Syndrome among University Students in Lebanon: Findings from a Cross-Sectional Study. World Journal of Gastroenterology, 21, 3628-3635. http://dx.doi.org/10.3748/wjg.v21.i12.3628

[13] World Gastroenterology Organization Global Guideline Irritable Bowel Syndrome: 2009. A Global Perspective.

[14] Drossman, D.A., Corazziari, E., Delvaux, M., Spiller, R.C., Talley, N.J., Thompson, W.G. and Whitehead, W.E. (2006) Rome III; the Functional Gastrointestinal Disorders. 3rd Edition, Degnon Associates, McLean, 917-951.

[15] Longstreth, G.F., Thompson, W.G., Chey, W.D., Houghton, L.A., Mearin, F. and Spiller, R.C. (2006) Functional Bowel Disorders. Gastroenterology, 130, 1480-1491. http://dx.doi.org/10.1053/j.gastro.2005.11.061

[16] Naeem, S.S., Siddiqui, U.E., Kazi, A.N., Memon, A.A., Khan, T.S. and Ahmed, B. (2012).Prevalence and Factors Associated with Irritable Bowel Syndrome among Medical Students of Karachi, Pakistan: A Cross-Sectional Study. BMC Research Notes, 5, 255. http://dx.doi.org/10.1186/1756-0500-5-255

[17] Shiotani, A., Miyanishi, T., et al. (2006) Sex Differences in Irritable Bowel Syndrome in Japanese University Students, Japan. Journal of Gastroenterology, 41, 562-568. http://dx.doi.org/10.1007/s00535-006-1805-2

[18] Al-Ghamdi, S., Al Osamey, F., Al-Hamdan, A., Binkhalaf, A., Alnujaydi, A., Turkistani, A., Al-Rasheed, A., Al-Shamrani, S., Al Quaydheb, A., Bin Ofaysan, M., Al Quraini, B., Bin Jupier, S. and Arneja, C. (2015) A Study of Impact and Prevalence of Irritable Bowel Syndrome among Medical Students. International Journal of Medicine and Medical Sciences, 7, 139-147.

[19] Liu, Y., Liu, L., Yang, Y., He, Y., Zhang, Y., Wang, M., Chen, S. and Shukun, Y. (2014) A School-Based Study of Irritable Bowel Syndrome in Medical Students in Beijing, China: Prevalence and Some Related Factors Hindawi Publishing Corporation. Gastroenterology Research and Practice, 2014, Article ID: 124261.

http://dx.doi.org/10.1155/2014/124261 